\title{
PREDICTING COGNITIVE REMEDIATION EFFICACY IN SCHIZOPHRENIA
}

Melo, B. ${ }^{1}$; Albuquerque,A. ${ }^{1}$; Correia, A. ${ }^{1}$; Gouveia, M. ${ }^{1}$; Alves Pereira, C. ${ }^{1}$, Pereira, S. ${ }^{1}$; Pires, I. ${ }^{1}$; Silva, G. ${ }^{1}$; Sousa, F. ${ }^{1}$; Monteiro, E. ${ }^{1}$

${ }^{1}$ Department of Psychiatry and Mental Health, Centro Hospitalar Tondela-Viseu, EPE., Viseu, Portugal

\section{Objectives:}

To present a non-systematic review of the literature about the predictors of Cognitive Remediation response.

\section{Background and aims:}

Cognitive challenges are one of the core symptoms of schizophrenia, causing great functional impairment in the individual, both psychosocial and occupational. Many cognitive remediation (CR) interventions have been developed and have demonstrated effect improving brain structure and function, performance on neuropsychological tests, community activities and social function.

Despite this, not all participants have significant improvements with CR.

Predictors of CR response, once established, may help in planning a more individualized intervention for each patient, in the future.

\section{Materials and methods:}

A literature search was conducted using the search engine Pubmed® and the keywords predictors, efficacy and cognitive remediation.

\section{Conclusions:}

Some of the most significant treatment positive response predictors are:

- Stable therapeutic alliance

- Smaller amounts of antipsychotics

- Motivated individuals

- Integrated intervention with other rehabilitation strategies

The identification of CR response predictors may be very useful in assisting patient referral, planning tailored intervention leading to increased intervention effectiveness and a more sustainable use of available resources.

References:

1. Best MW, Bowie CR. Expert Review of Neurotherapeutics A review of cognitive remediation approaches for schizophrenia: from top-down to bottom-up, brain training to psychotherapy. Expert Rev Neurother [Internet]. 2017;0(0). Available from: http://dx.doi.org/10.1080/14737175.2017.1331128

2. Hye W, Lee W. Cognitive rehabilitation for patients with schizophrenia in Korea. Asian J Psychiatr [Internet]. 2017;25:109-17. Available from: http://dx.doi.org/10.1016/j.aip.2016.10.010

3. Kurtz MM. Cognitive remediation for schizophrenia : current status , biological correlates and predictors of response. 2012;813-21

4. Deshpande SN, Bhatia T, Mohandas E, Nimgaonkar VL, Hospital ML, Street P, et al. HHS Public Access. 2017:124-8.

5. Barlati S, Deste G, Galluzzo A, Perin AP, Valsecchi P, Turrina C, et al. Factors Associated With Response and Resistance to Cognitive Remediation in Schizophrenia : A Critical Review. 2019:9(January):1-11.

6. Lindenmayer J, Ozog VA, Khan A, Ljuri I, Fregenti S, Mcgurk SR. Predictors of Response to Cognitive Remediation in Service Recipients With Severe Mental Illness. 2017:40(1):61-9.

7. Lindenmayer JP, Fregenti S, Kang G, Ozog V, Ljuri I, Khan A, et al. The relationship of cognitive improvement after cognitive remediation with social functioning in patients with schizophrenia and severe cognitive de fi cits. Schizophr Res [Internet]. 2017; Available from: http://dx.doi.org/10.1016/j.schres.2017.01.007

\section{Results:}

Several types of variables are identified as implicated in the to $\mathrm{CR}$. There are different variables involved, related to the patient, related to the intervention itself, and so

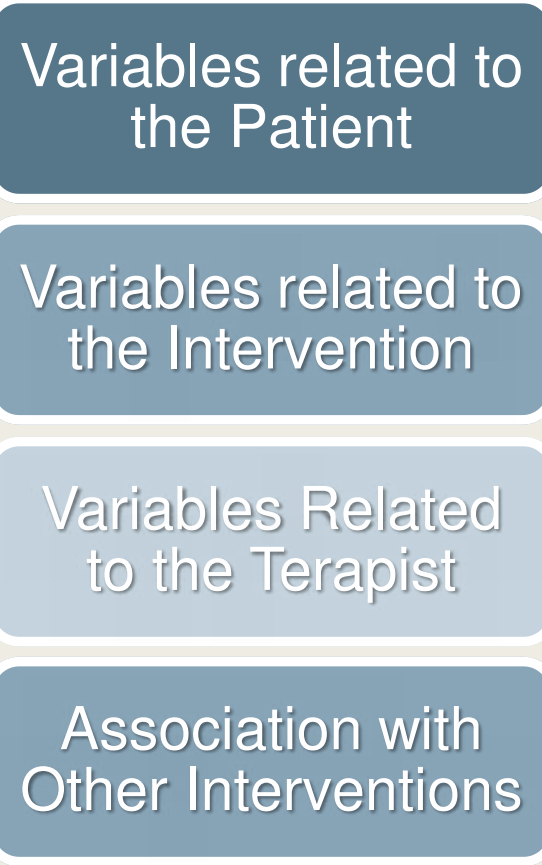

- Cognitive

- Psychological

- Biological

- Intensity

- Frequency

- Modality

The literature shows that the response to $\mathrm{CR}$ will be better in ounger patients, with a shorter disease course, fewer negative symptoms, disorganization and hostility at baseline and with greater pre-treatment cognitive reserve

en is delivered along with psychotherapy, , there is provement in the neuropsychological test performance community functioning. Psychotherapeutic component is necessary for improval, transcribed into day-life functionality. entic alliance promotes motivation, a very important Moreover, work style and clinician experience are important predictors of a positive response to CR treatment. 